\title{
OPTIMASI SUHU ANNEALING UNTUK EMPAT PRIMER RAPD PADA KACANG HIJAU (Vigna radiata L.)
}

\section{Optimizing Temperature Annealing for Four Primary RAPD in Mungbean (Vigna radiata $\mathrm{L}$.)}

\author{
Herman, Martupa Nainggolan, Dewi Indriyani Roslim \\ Jurusan Biologi, Fakultas Matematika dan Ilmu Pengetahuan Alam, \\ Universitas Riau, Kampus Bina Widya Km 12,5 Simpang Baru-Pekanbaru-Riau 28293 \\ Email: hermansyahdan@ymail.com dan dewiindriyaniroslim@gmail.com
} [Diterima Januari 2018; Disetujui: April 2018]

\begin{abstract}
Determination of annealing temperature of the primer is the first step for genetic diversity analysis using molecular markers such as RAPD (Random Amplified Polymorphic DNA). This study aims to determine annealing temperature (Ta) of RAPD primers on Kampar Mungbean. Methods included total DNA extraction, electrophoresis, and annealing temperature optimization of four RAPD markers namely OPD-20, OPI-06, OPI-13, dan OPX-13. Optimization was conducted by reducing the Tm value (Time melting) of each primer with $3(\mathrm{Tm}-3)$ and $5(\mathrm{Tm}-5)$. The results showed that the optimization using OPD-20 and OPX-13 produced bands at Tm-3 and Tm-5. Meanwhile, optimization using OPI-06 and OPI-13 resulted in bands at Tm-3. The next step was to choose the exact Ta based on the clear and bright band. In conclusion, exact Ta for OPD-20, OPI-06, OPI-13, and OPX -13 were $36,1^{\circ} \mathrm{C}, 38,1^{\circ} \mathrm{C}, 35,4^{\circ} \mathrm{C}$, and $32,5^{\circ} \mathrm{C}$ respectively.
\end{abstract}

Keywords: Annealing temperature, Genetic diversity, RAPD, Vigna radiata $\mathrm{L}$.

\begin{abstract}
ABSTRAK
Langkah awal analisis keanekaragam genetik kacang hijau menggunakan penanda RAPD (Random Amplified Polymorphic DNA) adalah menentukan suhu annealing pada primer RAPD yang akan digunakan. Penelitian ini bertujuan untuk menentukan suhu annealing $\left(T_{a}\right)$ empat primer RAPD pada kacang hijau asal Kampar. Prosedur penelitian meliputi isolasi DNA total, elektroforesis, dan optimasi suhu annealing pada empat primer RAPD, yaitu OPD-20, OPI-06, OPI-13, dan OPX13. Optimasi dilakukan dengan cara mengurangi nilai $\mathrm{T}_{\mathrm{m}}$ (Time melting) dari setiap primer dengan 3 $\left(\mathrm{T}_{\mathrm{m}}-3\right)$ dan $5\left(\mathrm{~T}_{\mathrm{m}}-5\right)$. Hasil optimasi menunjukkan bahwa primer OPD-20 dan OPX-13 menghasilkan pita pada suhu $T_{m}-3$ dan $T_{m}-5$. Primer OPI-06 dan OPI-13 menghasilkan pita pada suhu $T_{m}-3$. Tahap selanjutnya adalah memilih suhu annealing yang tepat, yaitu pita terang dan tegas pada suhu tersebut. Disimpulkan bahwa suhu annealing yang tepat untuk primer OPD-20, OPI-06, OPI-13, dan OPX-13 secara berturut-turut adalah $36,1^{\circ} \mathrm{C}, 38,1^{\circ} \mathrm{C}, 35,4^{\circ} \mathrm{C}$, dan $32,5^{\circ} \mathrm{C}$.
\end{abstract}

Kata kunci: Suhu annealing, Keanekaragaman genetik, $R A P D$, Vigna radiata $\mathrm{L}$.

PENDAHULUAN

Polymerase Chain Reaction (PCR) merupakan teknik sintesis dan amplifikasi DNA secara in vitro (Handoyo \& Rudiretna 2001). Teknik PCR meliputi tahapan denaturasi, penempelan primer (annealing), dan sintesis DNA (elongasi). Ketiga tahapan tersebut diulang-ulang 25 sampai 40 siklus. Setiap tahap dibedakan atas suhunya. Tahap denaturasi adalah tahap penguraian utas ganda DNA menjadi utas tunggal pada suhu tinggi, yaitu $\quad 94^{\circ} \mathrm{C}$ sampai $98^{\circ} \mathrm{C}$. Renaturasi (membentuk DNA untai ganda) akan terbentuk dengan cepat jika proses denaturasi berjalan tidak sempurna, hal ini akan mengakibatkan gagalnya proses PCR (Yusuf 2010). Tahap annealing adalah tahap penempelan primer pada DNA cetakan. Suhu annealing tergantung pada jumlah dan komposisi nukleotida penyusun 
primer (Suryanto 2003). Elongasi adalah tahap sintesis DNA yang dikatalisis oleh enzim DNA polimerase. Suhu untuk elongasi tergantung jenis enzim yang digunakan untuk PCR. Enzim DNA polimerase yang berasal dari mikroba Thermus aquaticus memiliki suhu optimum $72^{\circ} \mathrm{C}$ (Handoyo \& Rudiretna 2001).

Pada penelitian ini dilakukan optimasi suhu annealing pada empat primer RAPD (Random Amplified Polymorphic DNA), sebagai langkah awal untuk melakukan analisis keanekaragaman genetik pada tanaman kacang hijau asal Riau. Umumnya, kisaran suhu annealing berkisar $36^{\circ} \mathrm{C}$ sampai dengan $72^{\circ} \mathrm{C}$ dengan waktu 30-45 detik (Yusuf 2010). Optimasi suhu annealing suatu primer dapat dilakukan dengan cara mengurangi dan menjumlahkan nilai $\mathrm{T}_{\mathrm{m}}$ dengan $5^{\circ} \mathrm{C}$ (Handoyo \& Rudiretna 2000).

Penanda RAPD sering digunakan pada analisis keanekaragaman genetik karena relatif murah, mudah, cepat, primernya sudah tersedia secara komersial, dan tidak perlu informasi genom dari organisme yang diteliti (Prana \& Hartati 2003). Penanda RAPD (Random Amplified Polymorphic DNA) merupakan salah satu metode yang dapat digunakan dalam analisis DNA tanaman, dengan menggunakan teknik Polymerase Chain Reaction (PCR). Teknik PCR ini berguna menggandakan DNA hasil ekstraksi dalam jumlah kecil dan waktu singkat (William et al. 1990). Teknik ini melibatkan penempelan primer yang telah dirancang sesuai kebutuhan. Primer yang berukuran pendek menempel pada situs penempelan primer yang tersebar acak pada daerah di sepanjang DNA genom, sehingga membentuk utas DNA baru (Samal et al. 2003). Produk PCR yang terbentuk tergantung pada ada atau tidaknya situs penempelan primer pada DNA genom (NCBI 2011).

Reaksi PCR sangat dipengaruhi oleh konsentrasi komponen reaksi $\left(\mathrm{MgCl}_{2}\right.$, buffer, enzim DNA polimerase, DNA cetakan, primer, nukleotida, dan $\mathrm{H}_{2} \mathrm{O}$ ), suhu denaturasi, suhu penempelan primer pada DNA cetakan, suhu pemanjangan primer, jumlah siklus, serta keutuhan dan kemurnian DNA cetakan (Hallden et al. 1996). Penelitian ini bertujuan untuk menentukan suhu annealing yang tepat pada empat primer RAPD pada tanaman kacang hijau asal Kabupaten Kampar, Riau.

\section{BAHAN DAN METODE}

Penelitian dilaksanakan dari bulan Oktober-Desember 2016 di Laboratorium Genetika, Jurusan Biologi, Fakultas Matematika dan Ilmu Pengetahuan Alam, Universitas Riau.

Alat yang digunakan pada penelitian ini adalah tabung reaksi, timbangan digital, gelas beaker $100 \mathrm{ml}$ (Iwaki Pyrex), hot plate (Cimarec), pipet mikro (Socorex-Acura 825) ukuran $10 \mu \mathrm{l}, 200 \mu \mathrm{l}$ dan $1000 \mu \mathrm{l}$, tip mikro ukuran $10 \mu \mathrm{l}, 100 \mu \mathrm{l}$ dan $1000 \mu \mathrm{l}$, gunting, kertas parafilm, pinset, rak tabung, mesin sentrifuse (IEC Central CL2 Centrifuge), mesin waterbath (Precisdig), perangkat elektroforesis (Mupid-exU), mesin PCR (Multigene-Labnet International, inc), kamera digital (Olypmus SP-500 UZ), kulkas/ freezer, UV transiluminator (Wiseuv WUV-M20, Daihan Scientific), tabung $1,5 \mathrm{ml}$, tabung $0,2 \mathrm{ml}$, timbangan analitik (Ohaus), spatula, mortar dan pastel.

Bahan yang digunakan di dalam penelitan ini adalah daun muda kacang hijau berumur lima minggu yang berasal Kabupaten Kampar, akuades, nitrogen cair, isopropanol, kloroform, fenol, etanol 70\%, akuabidestilasi $\left(\mathrm{dH}_{2} \mathrm{O}\right), 10 \mathrm{X}$ TBE (Tris; Boric acid; EDTA), buffer TE, buffer CTAB $\left(\mathrm{dH}_{2} \mathrm{O} ; 1 \mathrm{M}\right.$ Tris- $\mathrm{HCl}$ $\mathrm{pH} 9 ; 5 \mathrm{M} \mathrm{NaCl} ; 0,5 \mathrm{M}$ EDTA; $14 \mathrm{M} \beta$ mercaptoetanol; 2\% CTAB), buffer TE (pH 8), Mix PCR (10 X buffer PCR; 2 mM dNTPs; 10 $\mu \mathrm{M}$ Primer; 5 unit/ $\mu \mathrm{l}$ Taq DNA polimerase; $\mathrm{dH}_{2} \mathrm{O} ; 100 \mathrm{ng} / \mu \mathrm{l}$ DNA) dan agarose.

Isolasi DNA Total dilakukan setelah tanaman kacang hijau berumur lima minggu. Isolasi DNA menggunakan metode CTAB (Saghai-Maroof et al. 1984) dengan sedikit modifikasi yaitu melakukan sentrifus dengan kecepatan 4000 rpm selama 10 menit setelah inkubasi. Larutan DNA total yang diperoleh disimpan pada suhu $-20^{\circ} \mathrm{C}$ sedangkan larutan DNA kerja disimpan di suhu $4^{\circ} \mathrm{C}$.

Elektroforesis DNA Total dilakukan pada $1,2 \%$ gel agarosa di dalam $1 \mathrm{X}$ buffer TBE, dengan tegangan 190 volt selama 20 menit. Hasil elektroforesis berupa gel diwarnai dengan $5 \mu \mathrm{g} / \mu \mathrm{l}$ etidium bromida. Pita DNA dideteksi menggunakan lampu UV, kemudian difoto menggunakan kamera digital.

Optimasi suhu annealing dilakukan pada 4 primer RAPD (Tabel 1). Total reaksi 
PCR yang digunakan sebesar $10 \mu \mathrm{l}$ dengan komponen PCR meliputi $1 \mu$ I DNA total, $1 \mathrm{x}$ buffer PCR, 0,1 mM dNTPs, 0,4 $\mu \mathrm{M}$ primer, dan 2 Unit Taq DNA Polimerase. Program PCR meliputi pra-PCR pada suhu $94^{\circ} \mathrm{C}$ selama 5 menit, diikuti 35 siklus dengan tiga tahapan, yaitu denaturasi pada suhu $94^{\circ} \mathrm{C}$ selama 45 detik, annealing pada suhu tergantung primernya (Tabel 1) selama 1 menit, dan elongasi pada suhu $72^{\circ} \mathrm{C}$ selama 1 menit 30 detik. Setelah itu, pasca PCR dengan suhu $72^{\circ} \mathrm{C}$ selama 10 menit.

Tabel 1. Suhu leleh $\left(\mathrm{T}_{\mathrm{m}}\right)$ dan suhu annealing $\left(\mathrm{T}_{\mathrm{a}}\right)$ pada empat primer RAPD

\begin{tabular}{|c|c|c|c|c|c|c|}
\hline \multirow{2}{*}{ Nama } & \multirow{2}{*}{ 5'------------3' } & \multirow{2}{*}{ mer } & \multirow{2}{*}{$\%(\mathrm{G}+\mathrm{C})$} & \multirow{2}{*}{$\mathrm{T}_{\mathrm{m}}\left({ }^{\circ} \mathrm{C}\right)$} & \multicolumn{2}{|c|}{$\mathrm{T}_{\mathrm{a}}\left({ }^{\circ} \mathrm{C}\right)$} \\
\hline & & & & & $\mathrm{T}_{\mathrm{m}}-5$ & $T_{m}-3$ \\
\hline OPD-20 & ACCCGGTCAC & 10 & 70 & 39,1 & 34,1 & 36,1 \\
\hline OPI-06 & AAGGCGGCAG & 10 & 70 & 41,1 & 36,1 & 38,1 \\
\hline OPI-13 & CTGGGGCTGA & 10 & 70 & 38,4 & 33,4 & 35,4 \\
\hline OPX-13 & ACGGGAGCAA & 10 & 60 & 37,5 & 32,5 & 34,5 \\
\hline
\end{tabular}

Elektroforesis Produk PCR dilakukan pada $1,5 \%$ gel agarosa di dalam $1 \mathrm{X}$ buffer TBE, dengan tegangan 80 volt selama 60 menit. Gel kemudian diwarnai dengan $5 \mu \mathrm{g} / \mu \mathrm{l}$ etidium bromida. Pita DNA dideteksi menggunakan lampu UV, kemudian difoto menggunakan kamera digital.

\section{HASIL DAN PEMBAHASAN Profil pita DNA Total Kacang Hijau}

Profil pita DNA total asal Kampar dapat dilihat pada Gambar 1. Weeden et al. (1992) menyatakan pita DNA yang redup atau tidak jelas disebabkan konsentrasi DNA total yang terlalu kecil. Pada penelitian ini, pita DNA total yang dihasilkan terang dan tebal. Pita yang terang dan tebal menunjukkan konsentrasi DNA total tersebut besar. Pita DNA total yang dihasilkan memiliki ukuran di atas 10.000 bp. Ketebalan pita yang dihasilkan akan mempengaruhi proses penggandaan DNA. Jika pita DNA tebal maka perlu dilakukan pengenceran.

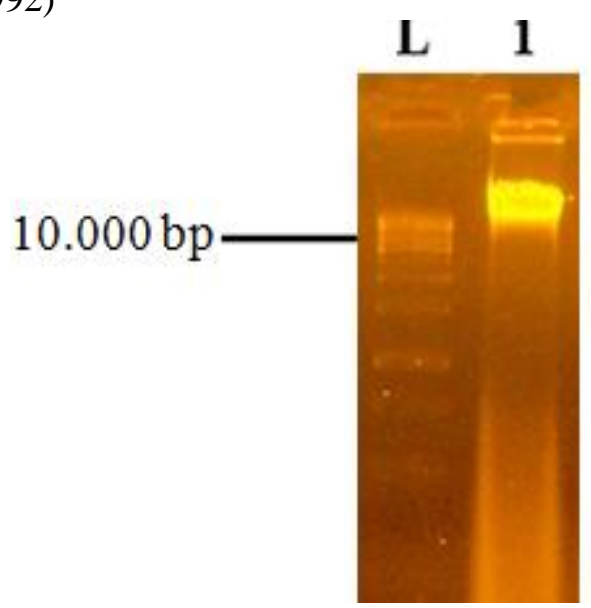

Gambar 1. Profil pita DNA total kacang hijau asal Kampar. Keterangan: (L) 1 kb DNA ladder (Thermo Scientific), (1) DNA total kacang hijau asal kabupaten Kampar

\section{Suhu annealing untuk primer RAPD}

Pita DNA hasil optimasi suhu annealing pada empat primer RAPD dapat dilihat pada Gambar 2. Setiap primer RAPD menghasilkan pola pita yang berbeda-beda. Selain itu, terdapat perbedaan intensitas dan ketegasan pita pada kedua suhu annealing dari setiap primer. Intensitas pita DNA dipengaruhi oleh: pertama, kemurnian dan konsentrasi DNA total. Jika DNA total yang digunakan mengandung fenolik, senyawa polisakarida, dan konsentrasi DNA rendah akan menghasilkan pita yang tidak jelas atau redup (Weeden et al. 1992). Kedua 
adalah situs penempelan primer pada DNA cetakan. Ketiga, kompetisi primer untuk menempel pada DNA cetakan sehingga ada DNA yang diamplifikasi dengan jumlah banyak dan fragmen yang lain sedikit. Tidak lebih dari 5000 pasang basa (pb) akan dihasilkan apabila situs penempelan primer masih berada pada jarak yang dapat diamplifikasi. Polimorfisme pita RAPD merupakan hasil dari perbedaan panjang DNA hasil amplifikasi (Grattapaglia et al. 1992).

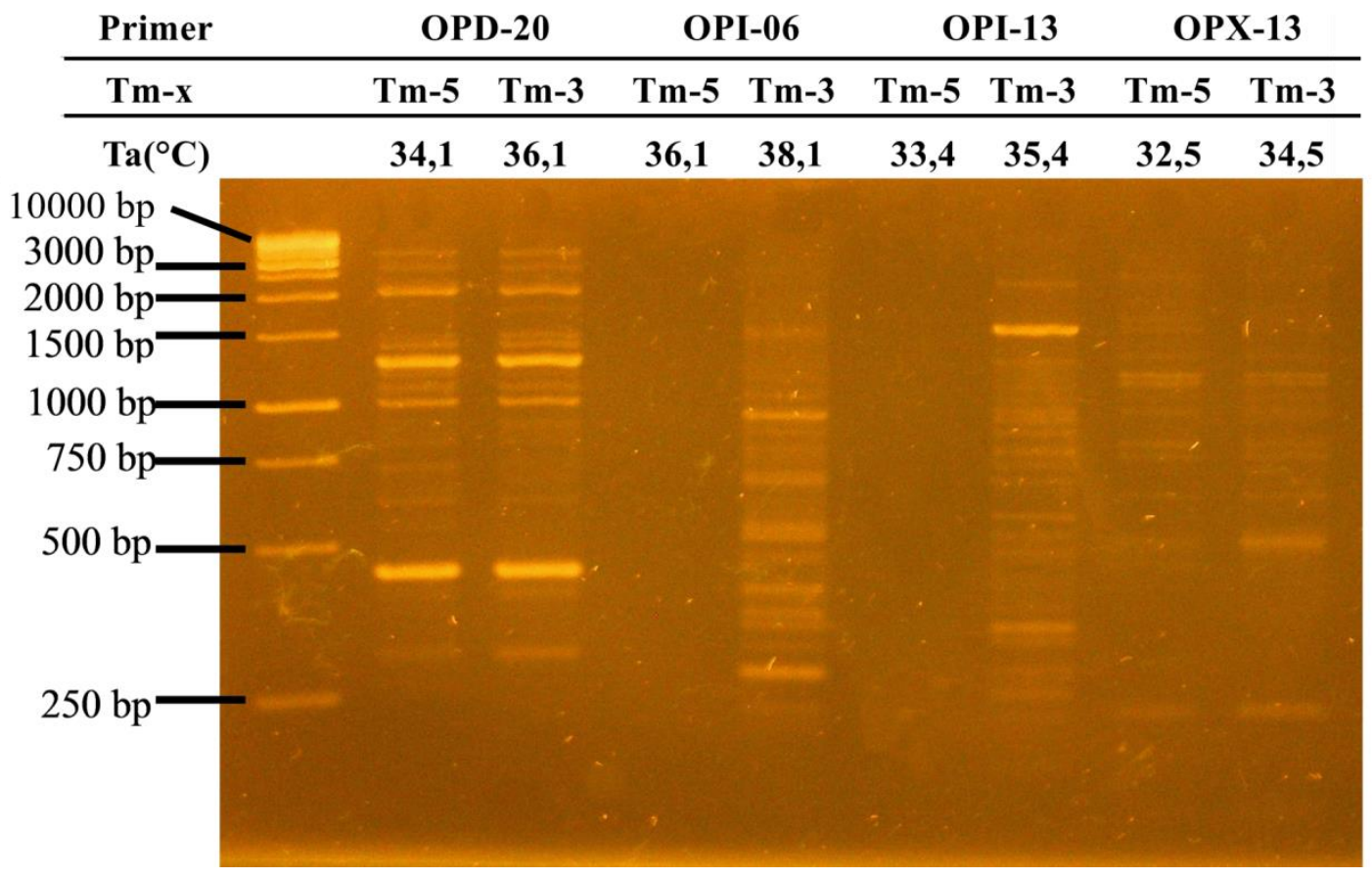

Gambar 2. Profil pita DNA hasil optimasi suhu annealing empat primer RAPD pada kacang hijau. Keterangan: (L) $1 \mathrm{~kb}$ DNA ladder, $\mathrm{T}_{\mathrm{a}}=$ suhu annealing, $\mathrm{T}_{\mathrm{m}}=$ suhu melting

Optimasi PCR dengan primer OPD-20 dan OPX-13 menghasilkan pita DNA pada $\mathrm{T}_{\mathrm{m}}$ dikurangi $3^{\circ} \mathrm{C}$ dan $5^{\circ} \mathrm{C}$. Primer OPD-20 pada $\mathrm{T}_{\mathrm{m}}$ dikurangi $3^{\circ} \mathrm{C}\left(36,1^{\circ} \mathrm{C}\right)$ dan primer OPX-13 pada $\mathrm{T}_{\mathrm{m}}$ dikurangi $5^{\circ} \mathrm{C}\left(32,5^{\circ} \mathrm{C}\right)$. Pada suhu annealing tersebut pita yang dihasilkan lebih tebal, terang, dan jelas. Berdasarkan kejelasan dan ketebalan pita DNA maka suhu annealing untuk empat primer RAPD pada tanaman kacang hijau asal kabupaten Kampar adalah primer $36,1^{\circ} \mathrm{C}$ untuk OPD-20, $38,1^{\circ} \mathrm{C}$ untuk OPI-06, $35,4^{\circ} \mathrm{C}$ untuk OPI-13, dan $32,5^{\circ} \mathrm{C}$ untuk OPX-13.

Hasil elektroforesis produk PCR menggambarkan jumlah dan ukuran pita (pola pita) yang berbeda-beda dari setiap primer. Grattapaglia et al. (1992) menyatakan bahwa perbedaan ini menggambarkan adanya genom tanaman yang kompleks. Williams et al. (1990) menyatakan bahwa banyaknya jumlah pita ini juga disebabkan banyaknya sebaran situs penempelan primer pada DNA cetakan.
Suryanto (2003) menyatakan proses penempelan primer pada DNA cetakan yang terbuka membutuhkan suhu optimum, sebab suhu yang terlalu rendah mengakibatkan primer menempel pada DNA genom yang bukan situsnya, sebaliknya suhu yang terlalu tinggi mengakibatkan proses amplifikasi tidak terjadi. Suhu penempelan primer (annealing) dipengaruhi oleh panjang dan komposisi primer.

\section{KESIMPULAN}

Suhu annealing untuk amplifikasi DNA kacang hijau asal kabupaten Kampar menggunakan primer OPD-20 adalah $36,1^{\circ} \mathrm{C}$, OPI-06 $38,1^{\circ} \mathrm{C}$, OPI- $1335,4^{\circ} \mathrm{C}$, dan OPX-13 $32,5^{\circ} \mathrm{C}$. 


\section{UCAPAN TERIMAKASIH}

Penulis mengucapkan terima kasih kepada Direktorat Riset dan Pengabdian Masyarakat-Direktorat Jendral Penguatan Riset dan Pengembangan-Kementerian Riset, Teknologi, dan Pendidikan Tinggi Republik Indonesia yang telah mendanai penelitian ini melalui Hibah Penelitian Unggulan Perguruan Tinggi tahun 2017 atas nama Herman, M.Sc, Ph.D.

\section{DAFTAR PUSTAKA}

Grattapaglia, D., Chaparro, J., Wilcox, P., McCord, S., Werner, D., Amerson, H., McKeand, S., Bridgwater, F., Whetten, R., O’Malley, D, Sederoff, R., 1992. Mapping in Wood Plants with RAPD Markers: Application to Breeding in Forestry and Holticulture. In: Aplication of RAPD Technology to Plant Breeding. Joint Plant Breeding Symposia Series CSSA/ASHS/AGA. 1 November 1992. Minneapolis. hlm. 37-40.

Hallden, C., M Hansen, Nilsson NO, Hjerdin, A. 1996. Competition as a Source of Errors In RAPD Analysis. Theor: Appl. Genet 93: 1185-1992.

Handoyo D., Rudiretna A. 2001. General Principles and Implementation of Polymerase Chain Reaction. Unitas 9 (1): 7.

Herman, Rahma, D., Roslim, DI., Rasyad, A., 2015. Genetic Diversity Analysis of Mungbean (Vigna radiata L.) from Riau Province Based on Morphological and Agronomic Characters. Di dalam: Proceedings SABRAO $13^{\text {th }}$ Congress and International Conference; Bogor, 14-16 September 2015. Bogor:IPB International Convention Center. hlm 105-115.

NCBI. 2011. National Center for Biological Information.

URL: http://www.ncbi.nlm.nih.gov/. [16 Maret 2017].

Prana TK, Hartati NS. 2003. Identifikasi Sidik Jari DNA Talas (Colocasia esculenta L. Schott) Indonesia dengan Teknik RAPD (Random Amplified Polymorphic DNA): Skrining Primer dan Optimalisasi Kondisi PCR. J. Natur Indonesia 5 (2): 107-112.
Saghai-Maroof MA, Soliman KM, Jorgensen RA, Allard RW. 1984. Ribosomal DNA Spacer-Length Polymorphisms In Barley: Mendelian Inheritance, Chromosomal Location, and Population Dynamics PNAS 81: 8014-8018.

Samal S, Rout GR, Lenka PC. 2003. Analysis of Genetic Relationship Between Population of Cashew (Anacardium occidentale L.) Using Morphological Characterisation and RAPD Markers. Plant Soil Environ 49(4): 176-182.

Suryanto D. 2003. Melihat Keanekaragaman Organisme Melalui beberapa Teknik Genetika Molekuler. USU Digital Library [terhubung berkala]. http://www.library.usu.ac.id/modules. php [07 Maret 2017]

Weeden, NF., GM., Timmerman, M., Hemmat., BE., Kneen, and MA., Lodhi. 1992. Inheritance and Reliability of RAPD Markers. In: Applications of RAPD Technology to Plant Breeding. Joint Plant Breeding Symposia Series, November 1, 1992, Minneapolis, MN. Crop Science Society of America, Madison, WI.

Williams, JGK, AR., Kubelik, KJ., Livak, JA., Rafalski and SV., Tingey. 1990. DNA Polymorphisms Amplified by Arbitrarily Primers are Useful as Genetic Markers. Nucleic Acids Research 18(22): 65316535

Yusuf, ZK. 2010. Polymerase Chain Reaction (PCR). Jurnal Saintek. Vol 5, Nomor 6. 
